\title{
A Comparison Study of Fatigue Behavior of Hard and Soft Piezoelectric Single Crystal Macro-Fiber Composites for Vibration Energy Harvesting
}

\author{
Mahesh Peddigari ${ }^{1}$, Ga-Yeon Kim ${ }^{1}$, Chan Hee Park ${ }^{1}$, Yuho Min ${ }^{1}$, Jong-Woo Kim ${ }^{1}$, \\ Cheol-Woo Ahn ${ }^{1}$, Jong-Jin Choi ${ }^{1}$, Byung-Dong Hahn ${ }^{1}$, Joon-Hwan Choi ${ }^{1}$, Dong-Soo Park ${ }^{1}$, \\ Jae-Keun Hong ${ }^{1}$, Jong-Taek Yeom ${ }^{1}$, Kwi-Il Park ${ }^{2}$, Dae-Yong Jeong ${ }^{3}$, Woon-Ha Yoon ${ }^{1}$, \\ Jungho Ryu ${ }^{4, *}$ and Geon-Tae Hwang ${ }^{1, *(D)}$ \\ 1 Korea Institute of Materials Science (KIMS), Changwon 51508, Korea; mahesh.p@kims.re.kr (M.P.); \\ gayeon713@kims.re.kr (G.-Y.K.); chpark@kims.re.kr (C.H.P.); yuhomin@kims.re.kr (Y.M.); \\ jwk@kims.re.kr (J.-W.K.); cheoruahn@kims.re.kr (C.-W.A.); finaljin@kims.re.kr (J.-J.C.); \\ cera72@kims.re.kr (B.-D.H.); jchoi@kims.re.kr (J.-H.C.); pds1590@kims.re.kr (D.-S.P.); \\ jkhong@kims.re.kr (J.-K.H.); yjt96@kims.re.kr (J.-T.Y.); zeppelin@kims.re.kr (W.-H.Y.) \\ 2 School of Materials Science and Engineering, Kyungpook National University, Daegu 41566, Korea; \\ kipark@knu.ac.kr \\ 3 Department of Materials Science and Engineering, Inha University, Incheon 22212, Korea; \\ dyjeong@inha.ac.kr \\ 4 School of Materials Science and Engineering, Yeungnam University, Gyeongsan 38541, Korea \\ * Correspondence: jhryu@ynu.ac.kr (J.R.); gthwang@kims.re.kr (G.-T.H.)
}

Received: 25 March 2019; Accepted: 9 May 2019; Published: 13 May 2019

\begin{abstract}
Designing a piezoelectric energy harvester ( $\mathrm{PEH})$ with high power density and high fatigue resistance is essential for the successful replacement of the currently using batteries in structural health monitoring (SHM) systems. Among the various designs, the PEH comprising of a cantilever structure as a passive layer and piezoelectric single crystal-based fiber composites (SFC) as an active layer showed excellent performance due to its high electromechanical properties and dynamic flexibilities that are suitable for low frequency vibrations. In the present study, an effort was made to investigate the reliable performance of hard and soft SFC based PEHs. The base acceleration of both PEHs is held at $7 \mathrm{~m} / \mathrm{s}^{2}$ and the frequency of excitation is tuned to their resonant frequency $\left(f_{\mathrm{r}}\right)$ and then the output power $\left(P_{\text {rms }}\right)$ is monitored for $10^{7}$ fatigue cycles. The effect of fatigue cycles on the output voltage, vibration displacement, dielectric, and ferroelectric properties of PEHs was analyzed. It was noticed that fatigue-induced performance degradation is more prominent in soft SFC-based PEH (SS-PEH) than in hard SFC-based PEH (HS-PEH). The HS-PEH showed a slight degradation in the output power due to a shift in $f_{\mathrm{r}}$, however, no degradation in the maximum power was noticed, in fact, dielectric and ferroelectric properties were improved even after $10^{7}$ vibration cycles. In this context, the present study provides a pathway to consider the fatigue life of piezoelectric material for the designing of PEH to be used at resonant conditions for long-term operation.
\end{abstract}

Keywords: energy harvesting; piezoelectric single crystal; long-term stability

\section{Introduction}

Over the past few years, research on vibration-based energy harvesting has increased tremendously by various groups across the globe. The main purpose of this research is to reduce the battery usage (or chemical waste) and to power the self-powered electronics by converting the ambient vibrations into electrical energy. Among the various vibration-based energy harvesting methods, including 
electromagnetic, electrostatic, piezoelectric, and triboelectric, the piezoelectric energy harvesting ( $\mathrm{PEH})$ is promising due to their ease of fabrication, structural integrity, high output power density and high conversion efficiency [1-4]. Among the various PEH configurations that have been examined for the efficient low frequency vibration energy scavenging, the cantilever based PEH is exceptional due to its simple structure and high root strain levels, which usually operates in bending mode to induce the in-plane strain in the cantilever structure according to the Euler-Bernoulli equation $[1,4]$. In general, the cantilever based PEH comprises of three essential parts including the elastic cantilever beam, piezoelectric layer, and proof mass. Numerous efforts have been made to improve the energy harvesting performance by optimizing the PEH configuration utilizing the materials with various strengths, dimensions, and strain levels [5-19]. In most cases, the maximum power is achieved under higher excitation levels due to the larger stress induced strains at the root of the cantilever. However, the application of such higher excitation forces often leads to performance degradation in the cantilever based PEHs. Therefore, a prior knowledge of behavior of the integral components under various excitation conditions is essential for designing high performance devices and for selecting the suitable materials to be used in specific applications.

Regarding the materials selection, depending on the excitation stimuli (frequency and acceleration), two kinds of piezoelectric materials-soft- and hard-type materials-have been widely utilized in harvesting applications [20-22]. In general, soft type piezoelectric materials exhibit higher piezoelectric coefficients and elastic compliances, which are more suitable for off-resonance excitations, whereas the hard type piezoelectric materials generate larger output power under resonant excitations owing to their larger mechanical quality factor. In order to improve the output performance in off-resonance conditions, a number of efforts such as non-linear dynamics and frequency-up conversion techniques were employed [23-27]. Thus far, piezoelectric materials have been used as active materials in cantilever based PEHs in various forms including thin/thick ceramic patches (or wafers), polymers, active fiber composites (AFC), macro-fiber composites (MFC), or single crystal macro-fiber composites (SFC) [3,28], in which the MFC/SFC configuration offers high mechanical flexibility, stress-strain performance, endurance, and electromechanical properties. Although many reports are available on the energy harvesting performance of PEHs based on MFC/SFCs [29-38], the investigation on the reliability (fatigue behavior) of SFCs under continuous electromechanical cyclic loading over a long time is rare [39-42].

Henslee et al. investigated the life-time performance of soft-type MFC (M-2807-P1, PZT 5A1, Smart Material Co., Dresden, Germany) based PEH up to $2.5 \times 10^{8}$ cycles by measuring the strain and tip displacements under the application of a particular voltage at different temperatures ranging between $15-145^{\circ} \mathrm{C}$ [40]. They reported that the performance of MFC was decreased continuously above $50{ }^{\circ} \mathrm{C}$. In another study, Deepesh et al. performed the fatigue test for soft-type MFC (M-2807-P2, PZT 5A1, Smart Material Co.) based PEH at different excitation conditions and noticed the severe degradation in the output voltage with a significant shift in the resonant frequency even below $0.5 \times 10^{6}$ cycles [41]. They proposed that the $600 \mu \varepsilon$ is the safe strain amplitude for the reliable operation over longer times. In another study, Panduranga et al. [42] investigated the damage propagation and different stages of fatigue failures in the soft type MFC (PZT 5A) based PEHs under various excitation levels in terms of change in the voltage and impedance values. Similarly, many reports are available on the fatigue behavior of soft-type piezoelectric materials and have discussed the fatigue life time, crack nucleation, and propagations. However, there are no reports available on the comparative studies on the fatigue behavior of soft- and hard-type SFC/MFCs under cyclic mechanical loads. Therefore, the present study intended to investigate the reliability performance of soft and hard SFCs at resonance condition under a constant excitation force (below the elastic limit) up to $10^{7}$ vibration cycles.

\section{Experimental details}

In the present study, two unimorph cantilever structured PEHs with two different $\mathrm{Pb}\left(\mathrm{Mg}_{1 / 3} \mathrm{Nb}_{2 / 3}\right) \mathrm{O}_{3}-\mathrm{Pb}(\mathrm{Zr}, \mathrm{Ti}) \mathrm{O}_{3}$ (PMN-PZT) based flexible SFCs fabricated by solid state grown method 
and electroded polyimide sheets lamination (Ceracomp. Co. Ltd., Korea) [35-38,43] were used as the active piezoelectric layers and a Ti alloy plate (elastic modulus of $55 \mathrm{GPa}$ ) was used as the passive elastic layer. Two NdFeB magnets $(3 \mathrm{~g})$ were used as a proof mass and attached at the free end of the cantilever. The Mn-doped PMN-PZT and W-doped PMN-PZT SFCs having the dimensions of $28(\mathrm{~L}) \times 14(\mathrm{~W}) \times 0.2(\mathrm{~T}) \mathrm{mm}^{3}$ were used as hard and soft piezoelectric materials, respectively (Figure 1a). The detailed manufacturing process of SFCs was reported in our previous study [32,33]. The SFCs were glued to a Ti alloy plate $\left[60(\mathrm{~L}) \times 20(\mathrm{~W}) \times 0.25(\mathrm{~T}) \mathrm{mm}^{3}\right]$ using an epoxy resin $\left(3 \mathrm{M}^{\mathrm{TM}}\right.$ Scotch-Weld Epoxy Adhesive DP-460 EG) and then cured at $70{ }^{\circ} \mathrm{C}$ for $3 \mathrm{~h}$. Further, the PEH was clamped with a rigid Bakelite holder and mounted on electromagnetic shaker for base excitation, as shown in Figure 1b.
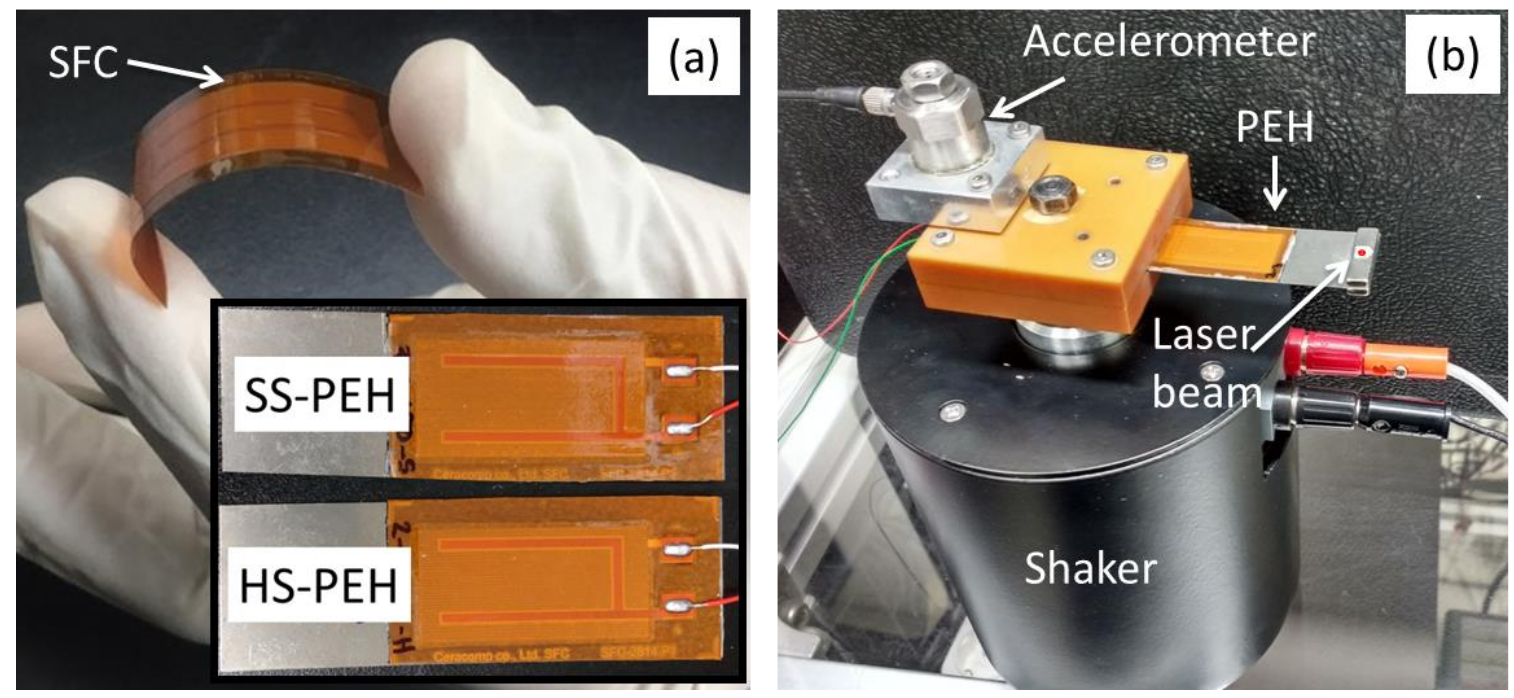

Figure 1. Photographs of (a) flexible single crystal-based fiber composites (SFC) and (b) experimental setup used for investigating the fatigue behavior of hard and soft SFC-based PEHs. The inset shows an image of soft and hard SFCs after attaching to the Ti-alloy elastic layer.

In order to investigate the reliable performance of hard and soft SFC-based PEHs, the specimens were tested up to $10^{7}$ fatigue cycles at a constant base acceleration of $7 \mathrm{~m} / \mathrm{s}^{2}(\sim 0.7 \mathrm{G})$ with $20 \sim 40 \mathrm{~Hz}$, i.e., vicinity of resonance frequency of the PEHs using an electromagnetic shaker. A vibration controller system (Logtech Co., Korea) used to control the shaker, which is connected with a feedback acceleration sensor (PV-41, RION, Japan) and a Laser Doppler vibrometry (LDV; OFV-5000, Polytec, Germany). The vibration displacement of PEHs in time domain is measured using the LDV. For given excitation conditions, the harvested (root mean square, RMS) voltage $\left(V_{\mathrm{rms}}\right)$ is measured across various load resistances $\left(R_{L}\right)$ embedded in a resistance decay box using a multi-channel multimeter (2700, Keithley, USA). Subsequently, the data were collected using National Instruments data acquisition systems and plotted the RMS power $P_{\text {rms }}\left(=\left(V_{\mathrm{rms}}\right)^{2} / R_{L}\right)$ versus number vibration cycles using a home-made software. The time-dependent output voltage waveforms were captured using an oscilloscope (Wave surfer 44Xs-A, Lecroy, USA). The dielectric properties of SFCs were measured using an impedance analyzer (4294A, Agilent Technologies). The polarization-electric field hysteresis loops of SFCs were measured at $1 \mathrm{kHz}$ using a ferroelectric tester (Precision LC-II, Radiant Technologies).

\section{Results and Discussion}

In order to know the resonant frequency $\left(f_{\mathrm{r}}\right)$ and optimum load resistance $\left(R_{\mathrm{opt}}\right)$ of both hard and soft SFC-based PEHs prior to test the fatigue behavior, the energy harvesting has been performed at an optimized base acceleration $\left(7 \mathrm{~m} / \mathrm{s}^{2}\right.$ ) condition (Figure S1) under different excitation conditions by varying the frequency $(20 \mathrm{~Hz}-40 \mathrm{~Hz})$ and load resistances $(1 \mathrm{k} \Omega-1000 \mathrm{k} \Omega)$. The $V_{\mathrm{rms}}$ response of both PEHs to the various load resistances $\left(R_{\mathrm{L}}\right)$ for different excitation frequencies is depicted in Figure 2a,b) 
and the corresponding $P_{\mathrm{rms}}\left(=\left(V_{\mathrm{rms}}\right)^{2} / R_{\mathrm{L}}\right)$ curves are shown in Figure $\left.2 \mathrm{c}, \mathrm{d}\right)$. Despite having identical geometry and acceleration excitation level, the PEHs exhibited different $f_{\mathrm{r}}$ and $P_{\mathrm{rms}}$ values due to the varied elastic compliance and electromechanical properties of SFCs (Table 1). The $f_{\mathrm{r}}$ values of the PEHs are identified from the maximum $P_{\text {rms }}$ (or $P_{\max }$ ) values, which are found to be $35.2 \mathrm{~Hz}$ and $33.5 \mathrm{~Hz}$ for HS-PEH and SS-PEH, respectively. The HS-PEH exhibited a relatively larger $P_{\max }$ of $3.18 \mathrm{~mW}$ at $47 \mathrm{k} \Omega$ as compared to SS-PEH sample $(2.53 \mathrm{~mW}$ at $20 \mathrm{k} \Omega)$ at the resonant condition.
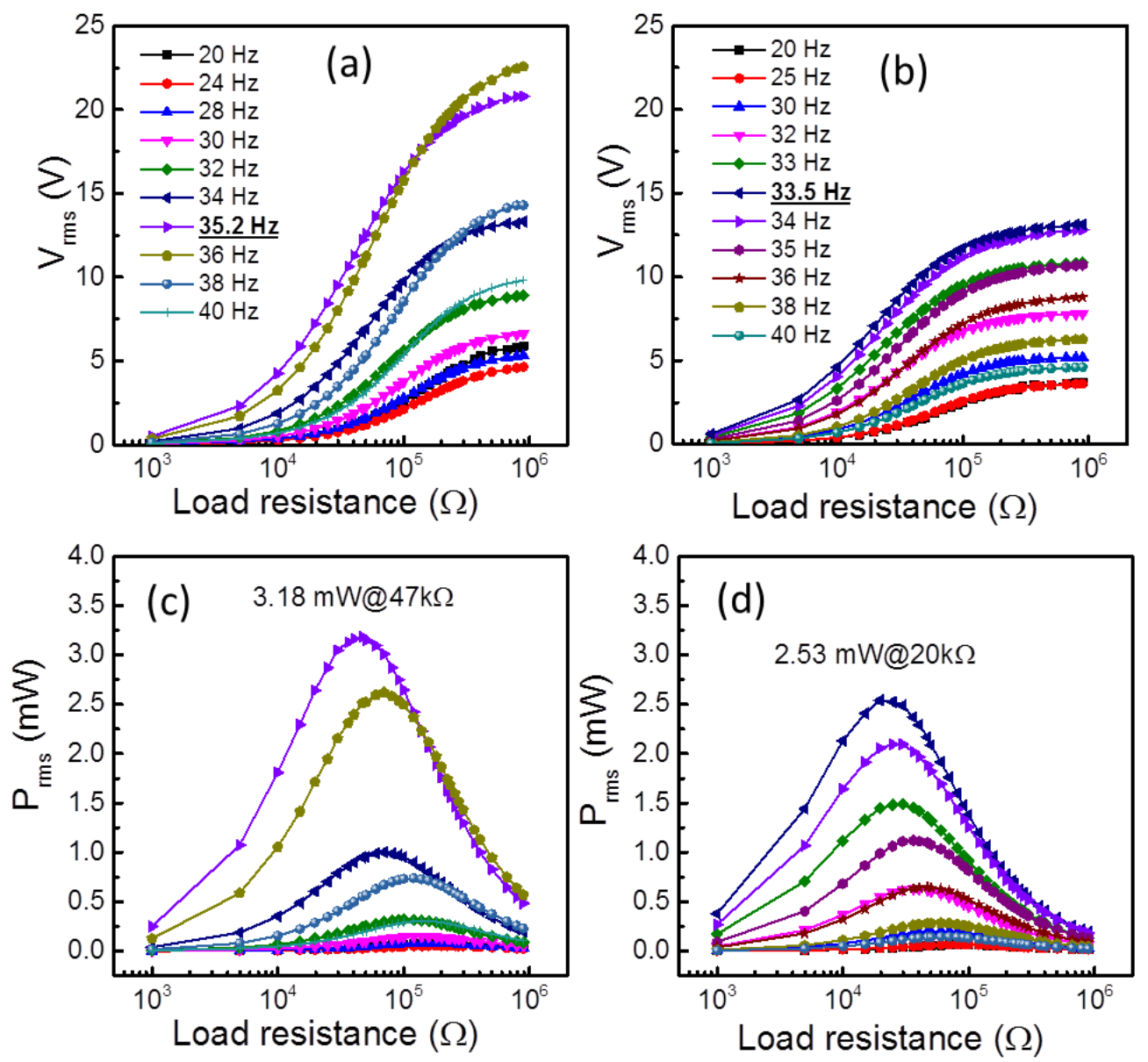

Figure 2. (a) and (c), (b) and (d) are the RMS voltage and RMS power curves for hard and soft SFC based piezoelectric energy harvesters (PEHs) measured as a function of load resistances at different excitation frequencies.

Table 1. Various material properties of soft- and hard-type SFCs.

\begin{tabular}{|c|c|c|c|c|}
\hline Parameter & Symbol & $\begin{array}{c}\text { Hard-Type SFC } \\
\text { (Mn-doped PMN-PZT) }\end{array}$ & $\begin{array}{c}\text { Soft-Type SFC } \\
\text { (W-doped PMN-PZT) }\end{array}$ & Units \\
\hline Density & $\rho$ & 7800 & 7900 & $\mathrm{~kg} / \mathrm{m}^{3}$ \\
\hline Volume & $(l \times b \times h)$ & $28 \times 14 \times 0.2$ & $28 \times 14 \times 0.2$ & $\mathrm{~mm}^{3}$ \\
\hline Dielectric constant & $\varepsilon_{33}$ & 2250 & 3962 & \\
\hline Dielectric loss & $\tan \delta$ & 0.0018 & 0.005 & \\
\hline Mechanical loss & $\tan \theta$ & 0.003 & 0.010 & \\
\hline Electromechanical coupling factor & $k_{32}$ & 0.697 & 0.726 & \\
\hline Piezoelectric charge constant & $d_{32}$ & -850 & -1850 & $10^{-12} \mathrm{C} / \mathrm{N}$ \\
\hline Elastic compliance & $s_{22} \mathrm{E}$ & 45.9 & 110.04 & $10^{-12} \mathrm{~m}^{2} / \mathrm{N}$ \\
\hline
\end{tabular}

By using the optimized conditions $f_{\mathrm{r}}\left(35.2 \mathrm{~Hz}\right.$ for HS-PEH and $33.5 \mathrm{~Hz}$ for SS-PEH) and $R_{\text {opt }}(47 \mathrm{k} \Omega$ for HS-PEH and $20 \mathrm{k} \Omega$ for SS-PEH), the fatigue measurement has been performed at an acceleration of $7 \mathrm{~m} / \mathrm{s}^{2}$ without interruption between the cycles. During the measurement, the harvested power 
$P_{\text {rms }}$ was collected after every $1 \mathrm{~h}$ and plotted using software and the process was continued until the $10^{7}$-oscillation period was reached. The output response of PEHs to the number of vibration cycles is shown in Figure 3. It is observed that the output $P_{\text {rms }}$ of HS-PEH is increased slightly with the vibration cycles up to $5 \times 10^{6}$ cycles (Figure $3 \mathrm{a}$ ), and decreased $(\sim 6.9 \%)$ further with increasing fatigue cycles, which might be due to the change in the $f_{\mathrm{r}}$. In the SS-PEH case, the output response deteriorated $(\sim 23.6 \%)$ continuously with increasing the vibration cycles, as shown in Figure $3 b$.
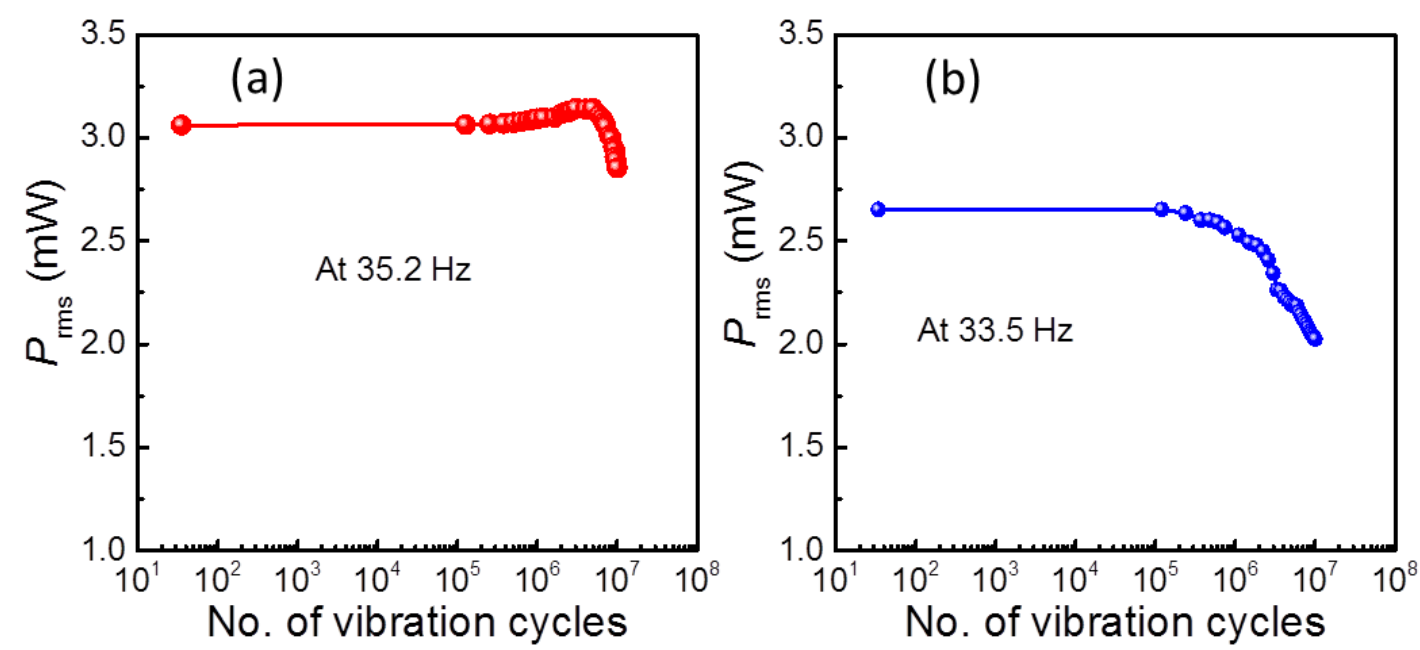

Figure 3. Variation in the $P_{\text {rms }}$ response of (a) hard SFC-based PEH (HS-PEH) and (b) soft SFC-based $\mathrm{PEH}(\mathrm{SS}-\mathrm{PEH})$ as a function of vibration cycles measured at $7 \mathrm{~m} / \mathrm{s}^{2}$.

In general, the output response of the PEH under a cyclic mechanical load over a period of time can be related to various parameters such as polarization change due to re-orientation of defect dipoles, migration of charge carriers at domain wall, microstructural changes (crack propagation), and resonant frequency shift due to change in the stiffness of PEH. In order to understand the damage caused by the fatigue in both PEHs, we have compared some directly observable parameters such as $f_{\mathrm{r}}, V_{\mathrm{rms}}$, dielectric properties, polarization-electric field $(P-E)$ loops, damping ratio, and vibration displacement $\left(d_{v}\right)$ before and after fatigue test in Figures 4 and 5 and Table 2.
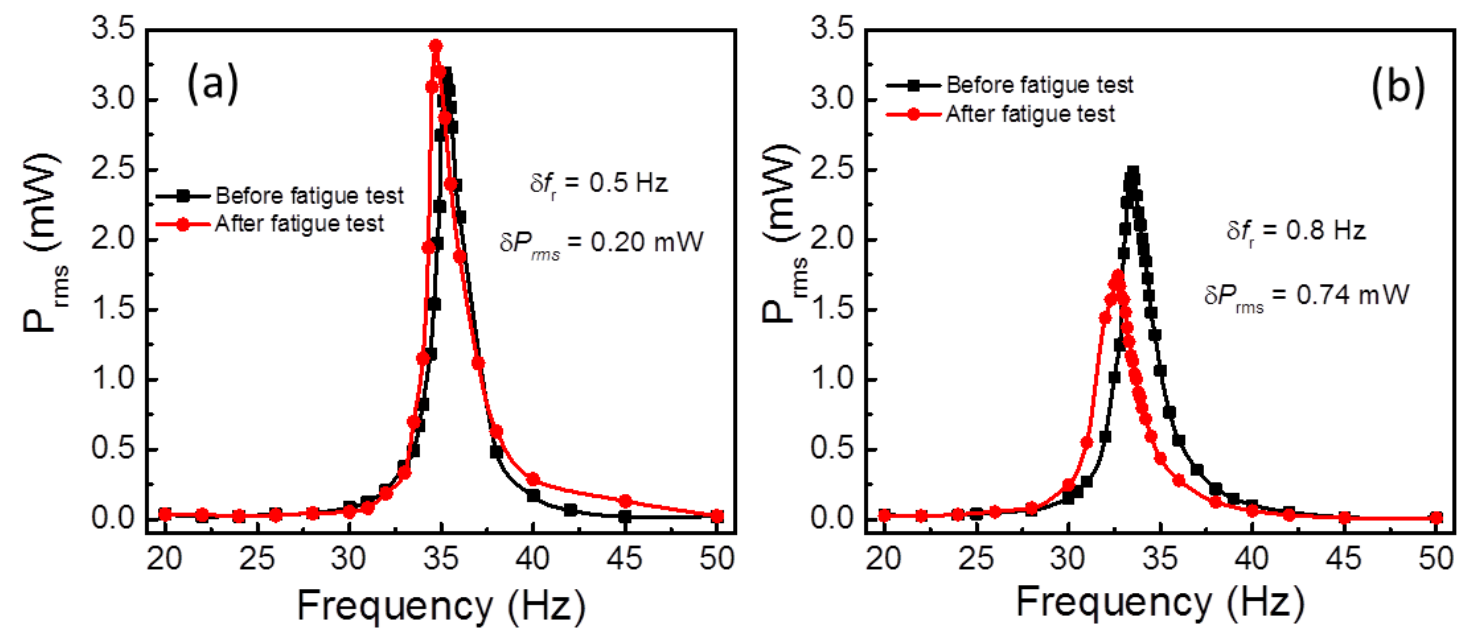

Figure 4. Comparison of power frequency response curves for (a) HS-PEH and (b) SS-PEHs measured at base acceleration of $7 \mathrm{~m} / \mathrm{s}^{2}$. 

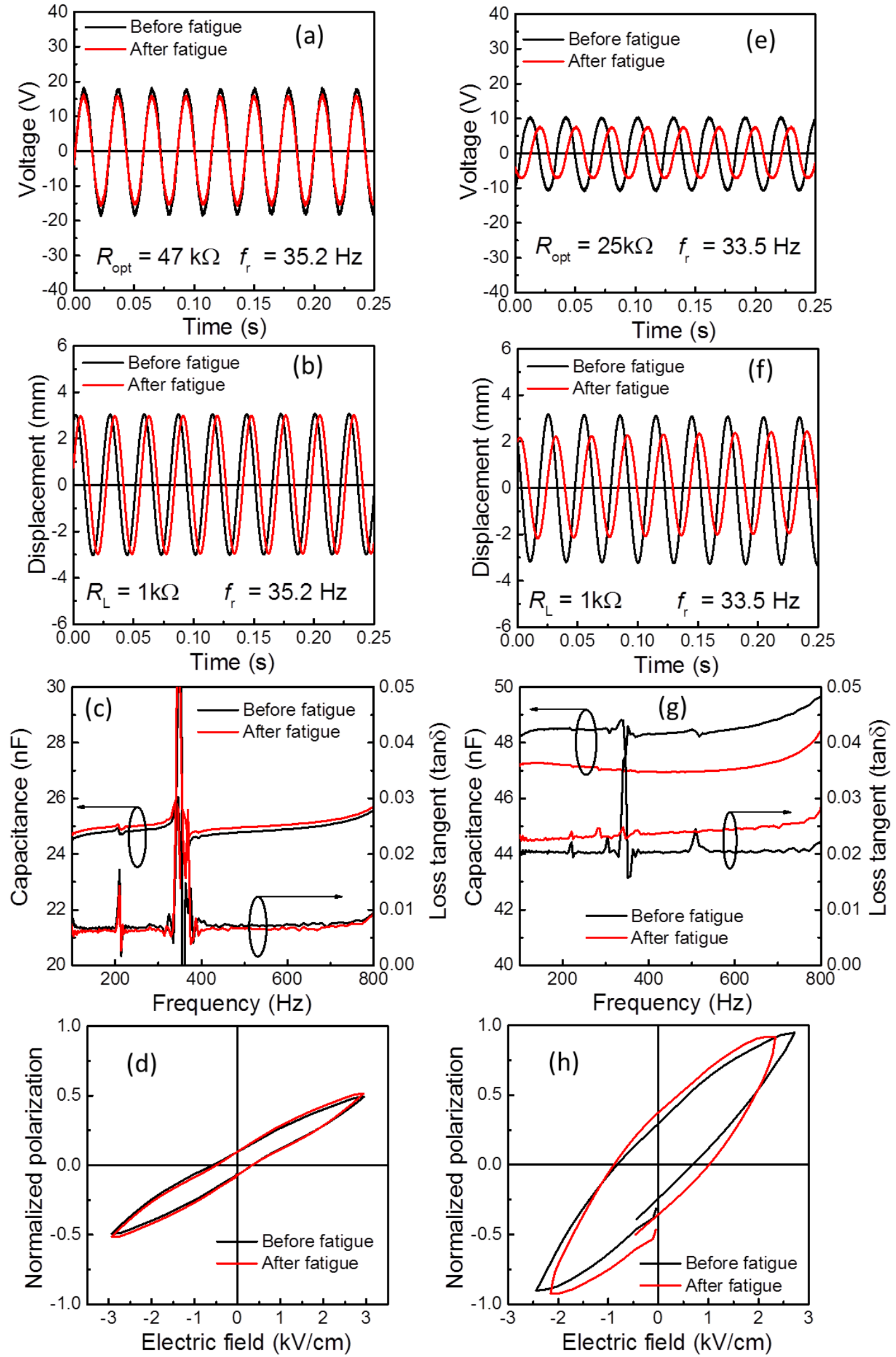

Figure 5. The comparison graphs of output voltage, vibration displacement, capacitance, and polarization changes for $(\mathbf{a}-\mathbf{d}) \mathrm{HS}-\mathrm{PEH}$ and $(\mathbf{e}-\mathbf{h})$ SS-PEHs measured before and after fatigue test at $7 \mathrm{~m} / \mathrm{s}^{2}$. 
Table 2. Changes in the energy harvesting characteristic parameters of PEHs after fatigue measurement.

\begin{tabular}{ccc}
\hline \multirow{2}{*}{ Parameter } & \multicolumn{2}{c}{ PEH Type } \\
\cline { 2 - 3 } & HS-PEH & SS-PEH \\
\hline$\Delta P_{\text {rms }}(\mathrm{mW})\left(\right.$ at initial $\left.f_{\mathrm{r}}\right)$ & $-6.9 \%$ & $-23.6 \%$ \\
$\Delta P_{\max }(\mathrm{mW})\left(\right.$ at final $\left.f_{\mathrm{r}}\right)$ & +0.20 & -0.74 \\
$\Delta f_{\mathrm{r}}(\mathrm{Hz})$ & -0.5 & -0.8 \\
$\mathrm{NVPD}\left(\mathrm{mW} / \mathrm{cm}^{3} \cdot \mathrm{Hz}^{2} \mathrm{~g}^{2}\right)$ & $+7.9 \%$ & $-27.5 \%$ \\
$\Delta d_{v}(\mathrm{~mm})\left(\right.$ at initial $\left._{\mathrm{r}}\right)$ & -0.04 & -1.20 \\
$\Delta C(\mathrm{nF})($ at $100 \mathrm{~Hz})$ & $+0.7 \%$ & $-2.1 \%$ \\
$P_{\mathrm{S}}\left(\mu \mathrm{C} / \mathrm{cm}^{2}\right)$ & $+4.7 \%$ & $-3.4 \%$ \\
Dielectric loss & $-16.2 \%$ & $+11.2 \%$ \\
Hysteresis loss & $+4.6 \%$ & $+20.6 \%$ \\
Mechanical loss (damping ratio) & $-0.3 \%$ & $+27.5 \%$ \\
\hline
\end{tabular}

The power frequency response curves for both PEHs before and after the fatigue test are presented in Figure $4 \mathrm{a}, \mathrm{b}$. It is noticed that the $f_{\mathrm{r}}$ for the HS-PEH decreased by $0.5 \mathrm{~Hz}$ in the span of $10^{7}$ vibration cycles, while the $P_{\max }$ and mechanical quality factor $\left(Q_{\mathrm{m}}\right)$ were enhanced by about $0.20 \mathrm{~mW}$ and $0.06 \mathrm{~mW}$, respectively. It can be understood that the abrupt drop in the power after $5 \times 10^{6}$ cycles (Figure 3a) is a result from the shift of $f_{\mathrm{r}}$ rather than the hard SFC performance degradation. From Figure $4 \mathrm{~b}$, the SS-PEH displayed a significant frequency shift in $f_{\mathrm{r}}(0.8 \mathrm{~Hz})$, reduction in $P_{\max }(0.74 \mathrm{~mW})$ and $Q_{\mathrm{m}}$ (3.52), along with a change in $R_{\mathrm{opt}}$ from $20 \mathrm{k} \Omega$ to $25 \mathrm{k} \Omega$ after $10^{7}$ vibration cycles. In spite of a maximum $f_{\mathrm{r}}$ shift towards the low-frequency side, the SS-PEH exhibited reduced output power and $Q_{\mathrm{m}}$, indicating the performance deterioration is merely due to SFC material degradation.

As shown in Figure 5a,e, the output voltages of both PEHs measured at optimized conditions $\left(f_{\mathrm{r}}\right.$ and $\left.R_{\mathrm{opt}}\right)$ show clear sinusoidal waves, which indicates that no cracks/damages were developed during the fatigue test (for post-test microstructural observation, see Figure S2). The HS-PEH show no significant reduction in the output voltage (Figure $5 \mathrm{a}$ ) and vibration displacement $\left(d_{v}\right)$ (Figure $5 \mathrm{~b}$ ) even after $10^{7}$ fatigue cycles, while the SS-PEH show a substantial drop in the $V$ and $d_{v}$ (Figure 5e,f) after fatigue test. In general, the maximum extractable power from a PEH depends on the base acceleration $(A)$, resonance frequency $\left(f_{\mathrm{r}}\right)$, and active (piezoelectric) layer volume (Vpiezo). In this context, the normalized volume power density $\left(\mathrm{NVPD}=P_{\max } /\left(V_{\text {piezo }} \cdot f_{\mathrm{r}} \cdot A^{2}\right)\right)$ was estimated for both PEHs [4]. The HS-PEH exhibited a relatively larger NVPD of $2.35 \mathrm{~mW} / \mathrm{cm}^{3} \cdot \mathrm{Hz} \cdot \mathrm{g}^{2}$ as compared to SS-PEH $\left(1.97 \mathrm{~mW} / \mathrm{cm}^{3} \cdot \mathrm{Hz}^{2} \mathrm{~g}^{2}\right)$. Similar to the $P_{\max }$, the NVPD also improved for HS-PEH by $7.9 \%$ and decreased by $27.5 \%$ for SS-PEH after fatigue measurement (Table 2 ).

Similarly, Deepesh et al. observed that a severe reduction in the output voltage (with a $55 \%$ drop of initial voltage) of soft-type MFC within $2 \times 10^{6}$ fatigue cycles at an acceleration of $6 \mathrm{~m} / \mathrm{s}^{2}$ when the induced strain amplitudes slightly higher than $1000 \mu \varepsilon$ [41]. Further, they suggested that the strain amplitude of $600 \mu \varepsilon$ is an upper limit for reliable performance of soft-type MFC. In another study, Panduranga et al. also performed the fatigue measurement for soft-type MFC at different acceleration levels $\left(4-6 \mathrm{~m} / \mathrm{s}^{2}\right)$ and stated that the MFC showed severe performance degradation at all the acceleration conditions and completely failed after $4.2 \times 10^{6}$ fatigue cycles when MFC operated at $6 \mathrm{~m} / \mathrm{s}^{2}$ with a maximum induced strain around $700 \mu \varepsilon$ [42]. In the present study, the maximum induced strains for the soft and hard SFCs used are slightly less than $300 \mu \varepsilon$ (Figure S3). Even though both SFCs showed crack-free behavior, the SS-PEH displayed severe performance degradation similar to the earlier reports, but the HS-PEH showed fatigue-free behavior with improved output power and mechanical quality factor.

Measuring the variation in piezoelectric properties of SFCs is a straightforward way to evaluate their fatigue ability, but since it is difficult, the dielectric and polarization properties were provided to supplement the piezoelectric properties. Figure $5 c$,g shows the dielectric properties such as capacitance (C) and loss tangent $(\tan \delta)$ of PEHs measured in the frequency range of $100-800 \mathrm{~Hz}$. The $C$ of the HS-PEH is enhanced by around $0.7 \%$ (at $100 \mathrm{~Hz}$ ) and reduced by $2.1 \%$ for SS-PEH, while the $\tan \delta$ 
is reduced for HS-PEH and is increased for SS-PEH after $10^{7}$ fatigue cycles. From Figure $5 \mathrm{~d}, \mathrm{~h}$, the ferroelectric properties (measured at $1 \mathrm{kHz}$ ) follow a similar trend to the dielectric properties. The saturation polarization $\left(P_{\mathrm{S}}\right)$ is slightly increased whereas the remanent polarization $\left(P_{\mathrm{r}}\right)$ and coercive field $\left(E_{\mathrm{C}}\right)$ remain constant for HS-PEH, while hysteresis loss is increased noticeably for SS-PEH after $10^{7}$ fatigue cycles.

As seen in Figure 3, a slight reduction in the output power of HS-PEH is noticed during the fatigue measurement (due to a shift in $f_{\mathrm{r}}$ ), although the final output power at resonance condition is improved. The improved $P_{\max }$ and $Q_{\mathrm{m}}$ after fatigue measurement might be related to the stabilization (or change) of domain wall configuration [44]. In general, the acceptor based defect dipoles prefer to occupy the energetically favored sites in the lattice and form anisotropic centers locally or within the domain [45]. Though there are no (few) grain boundaries in single crystal fibers, it may be possible to increase the diffusion of acceptor-based defect dipoles into domain walls and orientate defect dipoles in the direction of spontaneous polarization with the fatigue cycles, which increases the domain wall pinning and the intensity of internal dipolar field. Thus, the stabilization of domain walls in HS-PEH leads to improved dielectric, ferroelectric, and piezoelectric properties along with $Q_{\mathrm{m}}$. In the case of $\mathrm{SS}-\mathrm{PEH}$, it is assumed that the reduction in the output power with increasing the fatigue cycles is related to the increased domain wall mobility, which is facilitated by the donor dopant defect dipoles under the cyclic mechanical force. As the domain wall mobility increases, more mechanical energy dissipates, which eventually increases the piezoelectric losses and lowers the $f_{\mathrm{r}}$ and $Q_{\mathrm{m}}$ values [46]. This phenomenon is evidenced from the increased dielectric and ferroelectric losses and reduced $Q_{\mathrm{m}}$ and output power.

The lack of significant performance degradation in the output power and mechanical quality factor with fatigue cycles indicates that hard-type SFCs exhibit good fatigue endurance and are reliable for long-term piezoelectric energy harvesting at resonant conditions.

\section{Conclusions}

In this study, we have investigated the fatigue reliability performance of hard and soft SFC-based PEHs at constant base acceleration for the use in long-term energy harvesting applications. After $10^{7}$ fatigue cycles, the degradation in the output power and shift in the resonant frequency of soft SFC-based PEH are higher than that of hard SFC-based PEH. Indeed, the HS-PEH showed significant improvements in the output power, capacitance, and saturation polarization even after long cyclic vibration life, whereas the SS-PEH underwent continuous deterioration. Therefore, this study can be helpful for researchers to consider the fatigue effect and to select the appropriate piezoelectric material for long-term operation in piezoelectric energy harvesting applications.

Supplementary Materials: The following are available online at http://www.mdpi.com/1424-8220/19/9/2196/s1, Figure S1: The acceleration dependent rms power measured for hard-type and soft-type SFCs. Figure S2: Surface micrographs of the (a) hard-type and (b) soft-type SFCs after 107 vibration cycles. Figure S3: Simulation results for SS-PEH, performed using COMSOL Multiphysics. The induced (a) stress and (b) strain distributions in the soft SFC under the resonance excitation condition.

Author Contributions: Conceptualization: C.-W.A., D.-S.P., J.R. and G.-T.H.; Data curation: M.P., G.-Y.K., C.H.P., W.-H.Y. and G.-T.H.; Formal analysis: M.P., G.-Y.K., C.H.P., J.-W.K., J.-J.C., J.-T.Y., J.R. and G.-T.H.; Funding acquisition: W.-H.Y.; Investigation: J.-H.C. and G.-T.H.; Methodology: D.-S.P., J.-K.H. and J.-T.Y.; Project administration: W.-H.Y. and G.-T.H.; Resources: J.-H.C. and W.-H.Y.; Supervision, J.R. and G.-T.H.; Validation: J.-W.K. and J.-K.H., K.-I.P.; Writing—original draft: M.P., J.R. and G.-T.H.; Writing—review \& editing: M.P., Y.M., B.-D.H., K.-I.P., D.-Y.J., J.R. and G.-T.H.

Funding: Work at KIMS was supported by the National Research Council of Science \& Technology (NST) grant by the Korea government (MSIP) (No. CAP-17-04-KRISS), National Research Foundation of Korea (NRF) grant funded by the Korea government (MSIT) (No. 2019R1C1C1003765). Work at YU was supported by the Global Frontier R\&D Program on Center for Hybrid Interface Materials (HIM) funded by the Ministry of Science, ICT \& Future Planning Korea (Grant No. NRF-2016M3A6B1925390).

Conflicts of Interest: The authors declare no conflict of interest. 


\section{References}

1. Alper, E.; Inman, D.J. Piezoelectric Energy Harvesting; Wiley: Chichester, UK, 2011.

2. Romero, E.; Warrington, R.O.; Neuman, M.R. Energy scavenging sources for biomedical sensors. Physiol. Meas. 2009, 30, R35. [CrossRef]

3. Steven, R.A.; Henry, A.S. A review of power harvesting using piezoelectric materials (2003-2006). Smart Mater. Struct. 2007, 16, R1.

4. Priya, S.; Song, H.-C.; Zhou, Y.; Varghese, R.; Chopra, A.; Kim, S.-G.; Kanno, I.; Wu, L.; Ha Dong, S.; Ryu, J.; et al. A Review on Piezoelectric Energy Harvesting: Materials, Methods, and Circuits. Energy Harvest. Syst. 2017, 4, 3-39. [CrossRef]

5. Michael, W.S.; Matthew, B.; Ephrahim, G. Designing maximum power output into piezoelectric energy harvesters. Smart Mater. Struct. 2012, 21, 085008.

6. Miso, K.; John, D.; Brian, L.W. Efficiency of piezoelectric mechanical vibration energy harvesting. Smart Mater. Struct. 2015, 24, 055006.

7. Dhakar, L.; Liu, H.; Tay, F.E.H.; Lee, C. A new energy harvester design for high power output at low frequencies. Sens. Actuators A Phys. 2013, 199, 344-352. [CrossRef]

8. Aboulfotoh, N.; Twiefel, J. On developing an optimal design procedure for a bimorph piezoelectric cantilever energy harvester under a predefined volume. Mech. Syst. Signal Process. 2018, 106, 1-12. [CrossRef]

9. Wu, M.; Ou, Y.; Mao, H.; Li, Z.; Liu, R.; Ming, A.; Ou, W. Multi-resonant wideband energy harvester based on a folded asymmetric M-shaped cantilever. AIP Adv. 2015, 5, 077149. [CrossRef]

10. Song, H.-C.; Kumar, P.; Sriramdas, R.; Lee, H.; Sharpes, N.; Kang, M.-G.; Maurya, D.; Sanghadasa, M.; Kang, H.-W.; Ryu, J.; et al. Broadband dual phase energy harvester: Vibration and magnetic field. Appl. Energy 2018, 225, 1132-1142. [CrossRef]

11. Zhang, X.; Gao, S.; Li, D.; Jin, L.; Wu, Q.; Liu, F. Frequency up-converted piezoelectric energy harvester for ultralow-frequency and ultrawide-frequency-range operation. Appl. Phys. Lett. 2018, 112, 163902. [CrossRef]

12. Li, W.G.; He, S.; Yu, S. Improving Power Density of a Cantilever Piezoelectric Power Harvester Through a Curved L-Shaped Proof Mass. IEEE Trans. Ind. Electron. 2010, 57, 868-876. [CrossRef]

13. Yeo,H.G.; Trolier-McKinstry, S. Effect of piezoelectric layer thickness and poling conditions on the performance of cantilever piezoelectric energy harvesters on Ni foils. Sens. Actuators A Phys. 2018, 273, 90-97. [CrossRef]

14. Lee, M.-S.; Kim, C.-I.; Yun, J.-S.; Park, W.-I.; Hong, Y.-W.; Paik, J.-H.; Cho, J.-H.; Park, Y.-H.; Jeong, Y.-H. Comparison of Energy Harvesting Characteristics in Trapezoidal Piezoelectric Cantilever Generator with PZT Laminate Film by Longitudinal (3-3) Mode and Transverse (3-1) Mode. J. Korean Inst. Electr. Electron. Mater. Eng. 2017, 30, 768-775.

15. Yeo, H.G.; Ma, X.; Rahn, C.; Trolier-McKinstry, S. Efficient Piezoelectric Energy Harvesters Utilizing (001) Textured Bimorph PZT Films on Flexible Metal Foils. Adv. Funct. Mater. 2016, 26, 5940-5946. [CrossRef]

16. Lee, L.T.; Mohamed, M.A.; Yahya, I.; Kulothungan, J.; Muruganathan, M.; Mizuta, H. Comparison of piezoelectric energy harvesting performance using silicon and graphene cantilever beam. Microsyst. Technol. 2018, 24, 3783-3789. [CrossRef]

17. Palosaari, J.; Leinonen, M.; Juuti, J.; Jantunen, H. The effects of substrate layer thickness on piezoelectric vibration energy harvesting with a bimorph type cantilever. Mech. Syst. Signal Process. 2018, 106, $114-118$. [CrossRef]

18. Du, S.; Jia, Y.; Chen, S.-T.; Zhao, C.; Sun, B.; Arroyo, E.; Seshia, A.A. A new electrode design method in piezoelectric vibration energy harvesters to maximize output power. Sens. Actuators A Phys. 2017, 263, 693-701. [CrossRef]

19. Fu, H.; Chen, G.; Bai, N. Electrode Coverage Optimization for Piezoelectric Energy Harvesting from Tip Excitation. Sensors 2018, 18, 804. [CrossRef]

20. Erturk, A.; Lee, H.-Y.; Inman, D.J. Investigation of Soft and Hard Ceramics and Single Crystals for Resonant and Off-Resonant Piezoelectric Energy Harvesting. In Proceedings of the ASME 2010 Conference on Smart Materials, Adaptive Structures and Intelligent Systems SMASIS2010, Philadelphia, PA, USA, 28 September-1 October 2010; The American Society of Mechanical Engineers: Philadelphia, PA, USA, 2010; pp. 589-596.

21. Zhao, S.; Erturk, A. Deterministic and band-limited stochastic energy harvesting from uniaxial excitation of a multilayer piezoelectric stack. Sens. Actuators A Phys. 2014, 214, 58-65. [CrossRef] 
22. Shahab, S.; Zhao, S.; Erturk, A. Soft and Hard Piezoelectric Ceramics and Single Crystals for Random Vibration Energy Harvesting. Energy Technol. 2018, 6, 935-942. [CrossRef]

23. Harne, R.L.; Wang, K.W. A review of the recent research on vibration energy harvesting via bistable systems. Smart Mater. Struct. 2013, 22, 023001. [CrossRef]

24. Stanton, S.C.; McGehee, C.C.; Mann, B.P. Nonlinear dynamics for broadband energy harvesting: Investigation of a bistable piezoelectric inertial generator. Physica D 2010, 239, 640-653. [CrossRef]

25. Kathpalia, B.; Tan, D.; Stern, I.; Erturk, A. An experimentally validated model for geometrically nonlinear plucking-based frequency up-conversion in energy harvesting. Smart Mater. Struct. 2017, 27, 015024. [CrossRef]

26. Gu, L.; Livermore, C. Impact-driven, frequency up-converting coupled vibration energy harvesting device for low frequency operation. Smart Mater. Struct. 2011, 20, 045004. [CrossRef]

27. Dauksevicius, R.; Gaidys, R.; Ostasevicius, V.; Lockhart, R.; Vásquez Quintero, A.; de Rooij, N.; Briand, D. Nonlinear piezoelectric vibration energy harvester with frequency-tuned impacting resonators for improving broadband performance at low frequencies. Smart Mater. Struct. 2019, 28, 025025. [CrossRef]

28. Kim, H.S.; Kim, J.-H.; Kim, J. A review of piezoelectric energy harvesting based on vibration. Int. J. Precis. Eng. Manuf. 2011, 12, 1129-1141. [CrossRef]

29. Yaowen, Y.; Lihua, T.; Hongyun, L. Vibration energy harvesting using macro-fiber composites. Smart Mater. Struct. 2009, 18, 115025.

30. Hyun Jeong, S.; Choi, Y.-T.; Wereley, N.M.; Purekar, A.S. Energy Harvesting Devices Using Macro-fiber Composite Materials. J. Intell. Mater. Syst. Struct. 2010, 21, 647-658. [CrossRef]

31. Zhang, S.; Yan, B.; Luo, Y.; Miao, W.; Xu, M. An Enhanced Piezoelectric Vibration Energy Harvesting System with Macro Fiber Composite. Shock Vib. 2015, 2015, 7. [CrossRef]

32. Peddigari, M.; Lim, K.-W.; Kim, M.; Park, C.H.; Yoon, W.-H.; Hwang, G.-T.; Ryu, J. Effect of elastic modulus of cantilever beam on the performance of unimorph type piezoelectric energy harvester. APL Mater. 2018, 6, 121107. [CrossRef]

33. Kim, G.-Y.; Peddigari, M.; Lim, K.-W.; Hwang, G.-T.; Yoon, W.-H.; Choi, H.; Lee, J.W.; Ryu, J. Effect of Thickness Ratio in Piezoelectric/Elastic Cantilever Structure on the Piezoelectric Energy Harvesting Performance. Electron. Mater. Lett. 2019, 15, 61-69. [CrossRef]

34. Tan, D.; Yavarow, P.; Erturk, A. Resonant nonlinearities of piezoelectric macro-fiber composite cantilevers with interdigitated electrodes in energy harvesting. Nonlinear Dyn. 2018, 92, 1935-1945. [CrossRef]

35. Annapureddy, V.; Na, S.-M.; Hwang, G.-T.; Kang, M.G.; Sriramdas, R.; Palneedi, H.; Yoon, W.-H.; Hahn, B.-D.; Kim, J.-W.; Ahn, C.-W.; et al. Exceeding milli-watt powering magneto-mechano-electric generator for standalone-powered electronics. Energy Environ. Sci. 2018, 11, 818-829. [CrossRef]

36. Annapureddy, V.; Palneedi, H.; Yoon, W.-H.; Park, D.-S.; Choi, J.-J.; Hahn, B.-D.; Ahn, C.-W.; Kim, J.-W.; Jeong, D.-Y.; Ryu, J. A pT/ $\sqrt{ } \mathrm{Hz}$ sensitivity ac magnetic field sensor based on magnetoelectric composites using low-loss piezoelectric single crystals. Sens. Actuators A Phys. 2017, 260, 206-211. [CrossRef]

37. Annapureddy, V.; Kim, M.; Palneedi, H.; Lee, H.-Y.; Choi, S.-Y.; Yoon, W.-H.; Park, D.-S.; Choi, J.-J.; Hahn, B.-D.; Ahn, C.-W.; et al. Low-Loss Piezoelectric Single-Crystal Fibers for Enhanced Magnetic Energy Harvesting with Magnetoelectric Composite. Adv. Energy Mater. 2016, 6, 1601244. [CrossRef]

38. Annapureddy, V.; Lee, H.Y.; Yoon, W.-H.; Woo, H.-J.; Lee, J.-H.; Palneedi, H.; Kim, H.-J.; Choi, J.-J.; Jeong, D.-Y.; Yi, S.N.; et al. Enhanced magnetic energy harvesting properties of magneto-mechano-electric generator by tailored geometry. Appl. Phys. Lett. 2016, 109, 093901. [CrossRef]

39. Wilkie, W.; High, J.; Bockman, J. Reliability Testing of NASA Piezocomposite Actuators. In Proceedings of the 8th international Conference on New Actuators, Bremen, Germany, 10-12 June 2002; NASA Langley Research Center: Hampton, VA, USA, 2002.

40. Henslee, I.A.; Miller, D.A.; Tempero, T. Fatigue life characterization for piezoelectric macrofiber composites. Smart Mater. Struct. 2012, 21, 105037. [CrossRef]

41. Upadrashta, D.; Yang, Y. Experimental investigation of performance reliability of macro fiber composite for piezoelectric energy harvesting applications. Sens. Actuators A Phys. 2016, 244, 223-232. [CrossRef]

42. Avvari, P.V.; Yang, Y.; Soh, C.K. Long-term fatigue behavior of a cantilever piezoelectric energy harvester. J. Intell. Mater. Syst. Struct. 2016, 28, 1188-1210. [CrossRef]

43. Lee, H.-Y.; Ceracomp Co., Ltd. Available online: https://ceracomp.com (accessed on 4 February 2019). 
44. Zhao, J.; Zhang, Q.M. Effect of mechanical stress on the electromechanical performance of PZT and PMN-PT ceramics. In Proceedings of the ISAF '96. Proceedings of the Tenth IEEE International Symposium on Applications of Ferroelectrics, East Brunswick, NJ, USA, 18-21 June 1996; Volume 2, pp. 971-974.

45. Zhang, S.; Lee, S.-M.; Kim, D.-H.; Lee, H.-Y.; Shrout, T.R. Characterization of Mn-modified $\mathrm{Pb}\left(\mathrm{Mg}_{1 / 3} \mathrm{Nb}_{2 / 3}\right) \mathrm{O}_{3}-\mathrm{PbZrO}_{3}-\mathrm{PbTiO}_{3}$ single crystals for high power broad bandwidth transducers. Appl. Phys. Lett. 2008, 93, 122908. [CrossRef]

46. Uchino, K. Chapter 17-High-Power Piezoelectrics and Loss Mechanisms. In Advanced Piezoelectric Materials, 2nd ed.; Uchino, K., Ed.; Woodhead Publishing: Sawston, UK, 2017; pp. 647-754.

(C) 2019 by the authors. Licensee MDPI, Basel, Switzerland. This article is an open access article distributed under the terms and conditions of the Creative Commons Attribution (CC BY) license (http://creativecommons.org/licenses/by/4.0/). 